\title{
Homossexuais e sofrimento psíquico - homofobia em contexto intrafamiliar
}

\author{
Homosexuals and psychic suffering - homophobia in an \\ intrafamilial context
}

\author{
Hizabella de Andrade Barros Cruz', Laize Cedraz de Oliveira², \\ Roberta Lima Machado de Souza Araújo ${ }^{3}$
}

'Autora para correspondência. Universidade Estadual de Feira de Santana. Feira de Santana, Bahia, Brasil. ORCID: 0000-0002-2258-2190. habcruz@hotmail.com

2Universidade Estadual de Feira de Santana. Feira de Santana, Bahia, Brasil. ORCID: 0000-0002-1036-5228. ladi.cedraz@hotmail.com ${ }^{3}$ Universidade Estadual de Feira de Santana. Feira de Santana, Bahia, Brasil. ORCID: 0000-002-0302-2745. robertamachado.psi@gmail.com

RESUMO | A homossexualidade conceitua-se como uma condição ou característica de sujeitos que sentem atração física, emocional e/ou sexual por pessoas do mesmo sexo ou gênero. Nesta condição, encontra-se lésbicas, gays, bissexuais, transexuais, travestis, transgêneros e demais sujeitos que não se inserem ou não performam os modelos sociais normativos de gênero e sexualidade. Por sua vez, entende-se homofobia como um processo de tentativa de regulação de sexualidades, o qual atua desde ações de invisibilização e exclusão social, até violências físicas e/ou psicológicas. Essa tentativa reguladora de sexualidade acaba por oprimir os sujeitos dissidentes das concepções hegemônicas de sexualidade, sendo evidenciadas, em muitos casos, manifestações também nos contextos familiares, em que os sujeitos sofrem esses diferentes modos de violência, verificando-se desdobramentos nos aspectos psicossociais, como violência física, abusos psicológicos, chegando até a expulsão das suas casas. MÉTODo: Trata-se de uma revisão integrativa da literatura científica nacional, com objetivo de descrever as repercussões psicológicas das experiências de homofobia em contexto familiar. Utilizou-se de descritores correspondentes ao tema de interesse encontrados no DeCS para realizar pesquisas, combinando-os, nas bases de dados SciElo, MEDLINE, PepsiC e LiLACS. Em seguida foram realizadas leituras dos títulos e resumos, sendo selecionados artigos que trataram da relação entre homofobia em contexto familiar e sofrimento psíquico de homossexuais. RESULTADOS: O ambiente familiar o qual o homossexual está inserido organiza-se a partir das concepções de gênero, sexo e sexualidade, seguindo uma perspectiva heteronormativa e binária, que se legitima através de práticas discriminatórias de violência física e psicológica. Tais práticas violentas têm como consequência impactos na saúde mental dos indivíduos como a depressão, ideação e tentativa de suicídio, diminuição no desempenho escolar, assim como prejuízo na autoestima e no comportamento social dos homosseuxuais. CONSIDERAÇõES FINAIS: Verifica-se a necessidade da ampliação de estudos que voltem sua atenção à homofobia relacionada ao contexto familiar, em decorrência dos prejuízos psicossociais, a curto e longo prazo, que a vivência da discriminação nesses espaços gera nos indivíduos homossexuais, em função do vínculo emocional e de referência construído por eles e seu grupo familiar.
ABSTRACT | Homosexuality is conceptualized as a condition or characteristic of subjects who are physically, emotionally and / or sexually attracted to people of the same sex or gender. In this condition, there are lesbians, gays, bisexuals, transsexuals, transvestites, transgender people and other subjects who do not fit or perform the normative social models of gender and sexuality. In turn, homophobia is understood as a process of attempting to regulate sexualities, which acts from actions of invisibility and social exclusion, to physical and / or psychological violence. This attempt to regulate sexuality ends up oppressing dissenting subjects of hegemonic conceptions of sexuality, being evidenced, in many cases, manifestations also in family contexts, in which the subjects suffer these different modes of violence, and there are developments in psychosocial aspects, such as physical violence, psychological abuse and even expulsion from their homes. METHOD: This is an integrative review of the national scientific literature, aiming to describe the psychological repercussions of homophobia experiences in a family context. Descriptors corresponding to the topic of interest found in DeCS were used to conduct research combining them in the SciElo, MEDLINE, PepsiC and LiLACS databases. Then, titles and abstracts were read, and articles that dealt with the relationship between homophobia in the family context and psychosexual suffering of homosexuals were selected. RESULTS: The family environment in which the homosexual is inserted is organized from the conceptions of gender, sex and sexuality, following a heteronormative and binary perspective, which is legitimized through discriminatory practices of physical and psychological violence. Such violent practices have impacts on the mental health of individuals such as depression, ideation and suicide attempt, decreased school performance, as well as impaired self-esteem and social behavior of homosexuals. CONCLUSION: There is a need to expand studies that focus on homophobia related to the family context, due to the short- and long-term painful effects that the experience of discrimination in these spaces generates in homosexual individuals, due to the emotional bond and built by them and their family group.

KEYWORDS: Family. Family relationship. Homosexuality. Homophobia. Psychic suffering.

PALAVRAS-CHAVE: Família. Relação familiar. Homossexualidade. Homofobia. Sofrimento psíquico. 


\section{Introdução}

A homossexualidade é compreendida como atração física, emocional e/ou sexual por pessoas do mesmo sexo ou gênero, sendo evidenciada desde os primórdios da humanidade. (Ceccarelli, 2008). Evidências antropológicas registram que práticas homossexuais eram bem toleradas na Grécia, Pérsia, Roma e China, assim como em sociedades africanas. No Brasil dividia-se opiniões acerca das relações homossexuais, alguns aceitavam como condição da natureza humana, enquanto outros optavam pela rejeição absoluta dessas práticas (Ceccarelli, 2008).

Por outro lado, segundo Sarti (2004), família é um conjunto de sujeitos ligados por laços sanguíneos e laços de afeto, como também por interesses em comum que são compartilhados. Além disso, segundo a autora, família implica autoridade, pois há a função de socializar os menores, então a classificação seria como "...um mundo de relações recíprocas, complementares e assimétricas." (Sarti, 2004, p.18).

A revelação da homossexualidade na família pode causar uma relação conflituosa devido à frustração da não aceitação dos pais que muitas vezes agem violentamente ou de forma opressora, obrigando os filhos a manter sua orientação sexual em segredo para a sociedade e cobrando uma linearidade entre sexo e performance de gênero com a intenção de manter a lógica heteronormativa visando uma reintegração desse indivíduo as normas da sociedade (Braga; et al. , 2018).

Constata-se que, os sujeitos homossexuais que não respondem ao padrão normativo no contexto social acabam sofrendo psicologicamente, em função das fortes repressões sociais vivenciadas em contextos familiar (Perucchi, Brandão e Vieira, 2014; Braga, et al., 2018).

A dificuldade de aceitar as relações homoafetivas vem de uma construção social baseada em crenças e tabus, pautada em um padrão heteronormativo e patriarcal que prezam por uma continuidade desses padrões que não ameacem as ditas maiorias sociais.
Os que não se alinham a essas normas acabam enfrentando dificuldades de aceitação pela sociedade, estando expostos aos inúmeros tipos de violência, como a moral, psicológica ou até mesmo violência física, bullying, além da dificuldade em acessar direitos básicos como o de saúde.

Segundo Louro (2004), a sociedade ainda reproduz comportamentos discriminatórios frente a relacionamentos homoafetivos, comportamentos esses entendidos como homofóbicos. Essas atitudes têm então o objetivo de regular a sexualidade e a performance social com discursos de invisibilização, ações de violências sutis ou explícitas e dominação. Desse modo, sofrem com essas atitudes as pessoas que não se enquadram no padrão de heteronormatividade social, ou seja, gays, lésbicas, bissexuais, travestis, transgêneros, etc.

O momento de revelação da orientação sexual, também conhecido como "saída do armário", é entendido como a tomada de consciência e necessidade de socializar os seus desejos e preferências sexuais. Nesse momento o apoio da família é fundamental pois faz parte da construção de identidade do indivíduo. Uma vez que não ache esse apoio, o sujeito pode desencadear um processo de isolamento social, problemas de autoestima e de depressão.

Todavia, muitas famílias ao se depararem com a homossexualidade de um de seus membros, reagem com a rejeição do indivíduo homossexual, seguindo de violências sutis que vão desde fingir não saber da orientação sexual e obrigar a manter a ordem heterossexual, até a agressões verbais e físicas sérias. Além disso, muitas vezes o sujeito homossexual é expulso de casa, criando mais um estresse psicológico.

O estresse ou sofrimento psíquico é entendido pela psicanálise como sintomas, angústias, distúrbios, etc, os quais são apresentados por cada indivíduo de uma forma subjetiva e individual. No caso do sofrimento causado pela homofobia nos contextos intrafamiliares, destacam-se os sintomas associados ao sofrimento psíquico, tais como: isolamento social, problemas de autoestima, sintomas depressivos, crises de ansiedade. 
A família, então, que deveria ser o ambiente acolhedor e promotor do aumento da resiliência psicossocial, torna-se um ambiente hostil e de sofrimento, fazendo com que o sujeito tenha que buscar novas redes de apoio, principalmente quando é expulso de casa, as quais, muitas vezes, são compostas por amigos e pessoas que passaram pelas mesmas situações, e que juntas vão criando laços e aumentando as redes de apoio e cuidado.

Esse estudo teve como objetivo descrever as repercussões psicológicas das experiências de homofobia intrafamiliar, compreendendo como essas relações atuam na produção de sofrimento psíquico, levando em consideração a escassez de estudosdessa temática, o que dificulta o processo de compreensão e de estratégias de acolhimento e cuidado para essa população. Surge então a necessidade de pesquisas sobre a temática para uma maior compreensão e melhoria no cuidado.

\section{Método}

Trata-se de uma revisão integrativa acerca do sofrimento psíquico relacionado à homofobia no contexto intrafamiliar. Segundo Mendes (et al. 2008), a revisão integrativa é um método que busca agrupar e sintetizar resultados de pesquisas acerca de um tema ou questão possibilitando uma investigação no conhecimento científico aprofundada do assunto, além de mostrar lacunas que precisam ser preenchidas. Esse método de pesquisa possibilita um entendimento profundo sobre um determinado assunto, a partir de estudos já realizados. (Mendes et al., 2008)

Para o desenvolvimento de uma revisão integrativa deve-se, primeiramente, determinar o objeto a ser estudado, formulando um problema ou hipóteses. A partir disso, inicia-se a busca para identificar o maior número de pesquisas acerca do assunto, levando em consideração os critérios de inclusão e exclusão estabelecidos. Em seguida, o pesquisador revisa os estudos encontrados para determinar se são válidos, e nesse momento há uma redução no número de estudos. Ao final, coleta-se os dados dos estudos, analisando e interpretando para criar as conclusões a partir dos dados.
Para esse estudo, realizou-se um levantamento de descritores correspondentes ao tema de interesse na base de dados DeCS (Descritores em Ciência e Saúde), o qual possibilitou que se encontrasse os seguintes descritores: "família", "relações familiares" "estresse psicológico", "saúde mental", "minorias sexuais e de gênero", "homossexualidade masculina", "homossexualidade feminina", "homossexualidade", "bissexualidade", "comportamento sexual", "homofobia", "discriminação social" e "preconceito". Em conseguinte, utilizou-se os descritores encontrados para fazer uma busca nas bases de dados fazendo combinações entre os mesmos, as combinações feitas foram "homossexualidade and familia", "homossexualidade masculina and familia" "homossexualidade feminina and familia", "bissexualidade and familia", "minorias sexuais e de gênero and familia" "minorias sexuais e de gênero and relações familiares", "homossexualidade and relações familiares", "homossexualidade feminina and relações familiares", "homossexualidade masculina and relações familiares", "bissexualidade and relações familiares", "homofobia and familia", "homofobia and relações familiares". As bases de dados adotadas para esta pesquisa foram SciElo, MEDLINE, PepsiC e LiLACS. Durante as pesquisas nas bases de dados foram encontrados artigos repetidos ou artigos que não eram válidos segundo os critérios de elegibilidade desse estudo.

A identificação e escolha dos artigos seguiu os seguintes critérios de inclusão: artigos publicados na língua portuguesa e com qualquer data de publicação que estivessem nas bases de dados selecionadas. Os critérios de exclusão foram: artigos publicados em línguas estrangeiras, teses, monografias e livros. Após a pesquisa inicial, foi feita uma leitura dos resumos dos artigos para certificar se estavam de acordo com os objetivos do estudo e se eram válidos para a pesquisa.

Por fim foi feita a leitura completa dos artigos restantes após as filtragens, a partir disso foi criada uma tabela explicitando os fatores que relacionavam o sofrimento psíquico da população homossexual com a homofobia dentro do contexto intrafamiliar. Após isso foi feita a análise dos dados, com vistas a elaboração das considerações acerca do estudo. 


\section{Resultados}

Por meio do uso dos descritores nas bases de dados selecionadas, o processo de busca por literatura científica, dentro dos critérios de inclusão estabelecidos, alcançou como resultado oito artigos que respondiam a questão norteadora desta revisão, a qual se coloca sobre a compreensão de processos psicossociais, em jovens homossexuais, decorrentes de vivências homofóbicas dentro do contexto familiar. Tais artigos foram publicados em diferentes revistas voltadas para temáticas de psicologia, sendo somente um deles publicado em uma revista de enfermagem. Todos os artigos encontrados tiveram suas publicações inseridas no período entre os anos 2013 e 2018, o que demonstra o interesse dessa questão nas produções enquanto algo recente.

O quadro abaixo mostra a relação entre o número de artigos identificados em cada base de dados através da busca utilizando os descritores escolhidos, o número de artigos isolados, segundo os critérios de exclusão, e, por fim, após a leitura dos materiais, o número de artigos selecionados para esta pesquisa.

Quadro 1. Demostrativo das categorias elencadas. Florianóplis, 2017

\begin{tabular}{|l|c|c|c|}
\hline Base de Dados & Artigos Recuperados & $\begin{array}{l}\text { Artigos excluídos } \\
\text { Após os critérios de } \\
\text { exclusão }\end{array}$ & Artigos selecionados \\
\hline Scielo & 44 & 40 & 4 \\
\hline MEDLINE & 4 & 3 & 1 \\
\hline PepsiC & 25 & 22 & 3 \\
\hline LiLACS & 29 & 29 & 8 \\
\hline Total & 102 & 94 & 0 \\
\hline
\end{tabular}

Fonte: Os autores. 2019.

Nota-se, a partir das pesquisas realizadas, que os estudos voltados para os processos de revelação da sexualidade das pessoas homossexuais se mantém muito escassos, visto que, no que diz respeito às temáticas que envolvem homossexualidade, orientação sexual ou homofobia, grande parte das publicações nacionais voltam-se a questões relacionadas à HIV, infecções sexualmente transmissíveis, saúde pública, adoção, parentalidade homoafetiva, Teoria Queer e suicídio, afastando-se, nas publicações nacionais, pesquisas que demonstram uma atenção direcionada à compreender as relações de jovens homossexuais com o seu ambiente doméstico, bem como a violência familiar decorrente da homofobia nesses espaços. 
O quadro abaixo demonstra a relação entre os artigos encontrados e as respectivas bases de dados:

Quadro 1. Distribuição dos artigos segundo autor e indexadores

\begin{tabular}{|c|c|c|c|}
\hline Autores & Indexador & Autores & Indexador \\
\hline $\begin{array}{l}\text { Braga, I. F., Oliveira, W. A. } \\
\text { D., Silva, J. L. D., Mello, F. C. } \\
\text { M. D., \& Silva, M. A. I. } \\
\text { (2018). Violência familiar } \\
\text { contra adolescentes e } \\
\text { jovens gays e lésbicas: um } \\
\text { estudo qualitativo. Revista } \\
\text { Brasileira de Enfermagem- } \\
\text { REBEn, 71, 1295-1303. }\end{array}$ & SciELO & $\begin{array}{l}\text { Perucchi, J., Brandão, B. C., } \\
\text { \& dos Santos Vieira, H. I. } \\
\text { (2014). Aspectos } \\
\text { psicossociais da } \\
\text { homofobia intrafamiliar e } \\
\text { saúde de jovens lésbicas e } \\
\text { gays. Estudos de } \\
\text { Psicologia, 19(1), 67-76. }\end{array}$ & SciELO \\
\hline $\begin{array}{l}\text { de Lima Silva, M. M., } \\
\text { Frutuozo, J. F. F., Feijó, M. } \\
\text { R., Valerio, N. I., \& Chaves, } \\
\text { U. H. (2015). Família e } \\
\text { orientação sexual: } \\
\text { dificuldades na aceitação } \\
\text { da homossexualidade } \\
\text { masculina. Temas em } \\
\text { Psicologia, 23(3), 677-692. }\end{array}$ & PepsiC & $\begin{array}{l}\text { Soliva, T. B., \& da Silva } \\
\text { Junior, J. B. (2014). Entre } \\
\text { revelar e esconder: pais e } \\
\text { filhos em face da } \\
\text { descoberta da } \\
\text { homossexualidade. } \\
\text { Sexualidad, Salud y } \\
\text { Sociedad-Revista } \\
\text { Latinoamericana, (17), } \\
\text { 124-148. }\end{array}$ & SCIELO \\
\hline $\begin{array}{l}\text { Nascimento, G. C. M., \& } \\
\text { Scorsolini-Comin, F. } \\
\text { (2018). A Revelação da } \\
\text { homossexualidade na } \\
\text { família: revisão integrativa } \\
\text { da literatura científica. } \\
\text { Temas em Psicologia, } \\
\text { 26(3), 1527-1541. }\end{array}$ & PepsiC & $\begin{array}{l}\text { Toledo, L. G., \& Teixeira } \\
\text { Filho, F. S. (2013). } \\
\text { Homofobia familiar: } \\
\text { abrindo o armário 'entre } \\
\text { quatro paredes'. Arquivos } \\
\text { Brasileiros de Psicologia, } \\
\text { 65(3), 376-391. }\end{array}$ & PepsiC \\
\hline $\begin{array}{l}\text { Oliveira, L. D. (2019). A } \\
\text { "vergonha" como uma } \\
\text { "ofensa": } \\
\text { homossexualidade } \\
\text { feminina, família e } \\
\text { micropolíticas da emoção. } \\
\text { Horizontes } \\
\text { Antropológicos, (54), 141- } \\
171 .\end{array}$ & SCIELO & $\begin{array}{l}\text { Zanatta, E. A., Ferraz, L., } \\
\text { Klein, M. L., Marques, L. C., } \\
\text { \& Ferraz, L. (2018). } \\
\text { Descobrir, aceitar e } \\
\text { assumir a } \\
\text { homoafetividade: } \\
\text { situações de } \\
\text { vulnerabilidade entre } \\
\text { jovens/Discovering, } \\
\text { accepting and assuming } \\
\text { homoaffectivity: situations } \\
\text { of vulnerability among } \\
\text { young people. Revista de } \\
\text { Pesquisa: Cuidado é } \\
\text { Fundamental Online, } \\
\text { 10(2), 391-398. }\end{array}$ & MEDLINE \\
\hline
\end{tabular}

Fonte: Os autores. 2019. 
Todos os artigos selecionados para essa revisão caracterizam-se como pesquisa de abordagem qualitativa, um deles utilizando enquanto estratégia a observação participante, dois acessando os participantes pela técnica snow-ball e todos fazendo uso de entrevistas semiestruturadas ou abertas como metodologia para a coleta de dados.

Tais pesquisas tiveram em suas entrevistas e discussões como eixo central a busca por acessar e compreender, a partir do relato de jovens - homens e mulheres - homossexuais, aspectos das suas histórias de vida que são atravessadas pelo receio da descoberta por parte da família da homossexualidade, bem como pela reação familiar hostil frente a esta descoberta ou ao processo de "coming-out".

Os estudos selecionados tratam o processo de "saída do armário" de jovens gays e lésbicas e os aspectos que o envolvem dentro dos lócus familiares, compreendendo os conflitos que podem surgir entre os familiares em decorrência dessa revelação ou descoberta, tal como os fatores adoecedores que constituem esses conflitos, os quais são determinados pela homofobia inserida nesse ambiente.

Após a leitura e análise dos artigos, percebe-se os diferentes modos através dos quais a homofobia se manifesta nas relações familiares. Violências a nível psicológico, simbólico e físico se fazem presentes e suas consequências na saúde mental dos indivíduos, em certos casos, nem sequer são percebidas, visto que há uma relativização dessas práticas em decorrência da forma pela qual atuam - no cotidiano através de "piadas", invisibilização, exclusão, silenciamento, etc. - no contexto intrafamiliar no qual ela se insere.

\section{Discussão}

Apesar da família ser recoberta no imaginário popular por uma perspectiva que a coloca enquanto núcleo de segurança, apoio e acolhimento para os indivíduos que a compõe, os estudos realizados mostram que os contextos familiares, em sua maioria, mantêm-se a partir de certas determinações e exigências que são previamente baseadas nas normas sociais heteronormativas vigentes.
Nesse sentido, a família, ou, mais precisamente, o espaço familiar enquanto ambiente de agregação aos seus indivíduos toma como necessidade prévia seu funcionamento a partir de concepções de gênero, sexo e sexualidade que se adequem aos modelos hegemônicos de uma sociedade organizada por uma perspectiva binária e heteronormativa desses aspectos. Assim sendo, há nas relações familiares cobranças para que seus membros atuem seguindo as condutas esperadas socialmente.

As autoras Perucchi, Brandão e Vieira (2014) e Braga, et al. (2018) trazem em seus estudos que o sujeito que, de algum modo, desvirtua dessas regras que configuram o convívio familiar, sofre repressões através de mecanismos violentos na tentativa de serem novamente fixados na norma. Nesse sentido, a família reage a esse novo cotidiano, não mais promovendo a saúde e a dignidade do sujeito, e se apresenta como uma ferramenta de reforço do imperativo da heteronormatividade, por meio da violência e inferiorização das subjetividades que negam essa heteronorma.

Ainda nessa perspectiva, as autoras trazem como consequência da hostilidade nas relações familiares, a busca dos indivíduos por redes de apoio que incluem pessoas/amigos fora da dinâmica familiar. Sendo assim, em virtude das situações de sofrimento advindas da homofobia, essas pessoas tendem a formar laços que, apesar de não serem pautados no sangue e não serem identificados normalmente como família, são tomados pelo sujeito por esse significado, visto que, apesar de frágeis, são nessas redes de amizade que eles encontram algum tipo de escuta e apoio para lidar com as violências provocadas pela família (Perucchi, Brandão \& Vieira, 2014).

De acordo com o estudo de Teixeira e Toledo (2013), as pessoas entrevistadas colocaram a homofobia dentro de casa como o pior tipo de discriminação vivenciada. Nesse estudo, as participantes relataram o "sair do armário" para os pais como um processo turbulento, circunscrito por mecanismos de "controle, vigilância, perseguição, invasão de privacidade, proibições, ameaças, chantagens e até agressões" (p. 384). Entre os modos de exercer esse tipo de controle sobre as vivências dos jovens, está a proibição imposta aos filhos de estarem inclusos em ciclos sociais que envolvem pessoa não heterossexuais ou 
o impedimento de receberem em suas casas seus amigos - principalmente gays - na tentativa de fazer esse jovem regressar ao modo de vida determinado (Soliva \& Silva, 2014). Nesse sentido, percebe-se que, até mesmo as estratégias de proteção e autocuidado as quais esses jovens homossexuais tendem a buscar, como a formação de vínculos com demais pessoas que os acolha e compreendam, são ameaçadas ou mesmo suprimidas, dificultando os meios de aliviar o sofrimento continuamente vivido.

O estudo realizado por Braga et al. (2018) reafirma essa inserção da violência no cotidiano dos homossexuais, mostrando que, a partir do momento da revelação "a família se apresenta enquanto cenário de conflitos e de violências, tanto físicas quanto psicológicas" (p. 1300), as quais se apresentam de modo sutil ou explícito, levando os jovens a identificar esse ambiente como permeado por, ademais as violências anteriormente citadas, julgamentos morais e religiosos por parte dos pais e familiares. Como evidenciado na pesquisa de Zanatta et al. (2018), a dificuldade dos pais em aceitar o filho desviante da heterossexualidade muitas vezes é um reflexo das crenças religiosas, sendo frequente a visão da homoafetividade como uma doença ou pecado, sendo visto como doente.

Verifica-se assim que essa violência é introduzida nessa relação como parte do próprio cotidiano. Uma das constatações do estudo de Perucchi, Brandão e Vieira (2014) foi o fato de que não é a expulsão de casa o que configura o extremo do sofrimento decorrente da homofobia intrafamiliar, mas sim as diferentes formas de violação que se inserem no cotidiano dos indivíduos de forma sistemática, marcando suas subjetividades através de constantes modos de humilhação e exclusão as quais são submetidos quando pertencentes a esse contexto heteronormativo que tende a ter essas práticas justificadas pela autoridade que usualmente se garante à instituição familiar.

A partir disso, tal autoridade, usualmente afirmada pela cultura, pode representar um agravante visto que supõe-se o contexto familiar como um ambiente privado o qual não cabem interferências alheias de forma direta que visem intervir e, de certo modo, anular as relações de poder estabelecidas, mesmo que delas derivem marcas de violência, o que, por sua vez, tende a legitimar estruturas familiares promotoras de sofrimento.
Nesse sentido, pensando as consequências dessa conformidade das práticas violentas para a saúde mental, as autoras Perucchi, Brandão e Vieira (2014) apontam a negação ou minimização dos efeitos psicossociais da homofobia nos sujeitos, os quais acabam por não reconhecer a priori essa homofobia e, por conseguinte, não reconhecem a implicação da mesma em sua saúde e processos de subjetivação.

Dentro desse contexto de discriminação instaurada no cotidiano, é importante destacar o peso da violência simbólica estabelecida por pais aos(às) filhos(as) homossexuais, utilizando diferentes formas de silenciamento e inferiorização como modos de impedir o sujeito de vivenciar a sua sexualidade abertamente, reprimindo e invisibilizando seus modos de expressão e de ser/estar no mundo.

É, em alguns casos, através dessa violência simbólica que certas naturalizações da homofobia se fazem possível, como se fez perceber em entrevistas na pesquisa de Perucchi, Brandão e Vieira (2014), onde as autoras relatam casos de jovens que vivenciaram experiências de práticas homofóbicas intrafamiliar, por meio de "piadas", deboches e tratamentos diferenciados, porém, apesar de terem consciência dessa discriminação, não reconheceram essas atitudes como tais.

Essa naturalização, para além de ter como critério a ocorrência da homofobia em meio ao cotidiano, tem como fator essencial a relação de afeto na qual essa discriminação está envolvida. Visto que, o fato dos agressores - seja agressão física, material, simbólica ou psicológica - serem pessoas com quem o sujeito mantém um vínculo afetivo, é um ponto determinante para que o indivíduo nem sequer reconheça essa atitude como agressão, o que consequentemente dificulta também que se perceba os efeitos disso na própria saúde mental (Perucchi, Brandão \& Vieira, 2014).

A homofobia intrafamiliar carrega consigo ainda mais um peso advindo do fato da discriminação se dar nos laços familiares, tendo em vista que, em práticas homofóbicas fora do contexto da casa, ao invés dos agressores serem pessoas desconhecidas e não inseridas no convívio do indivíduo, eles, que promovem tais práticas dentro da casa, são referências sociais e afetivas de suas vítimas. Nesse sentido, Soliva e Silva Junior (2014) colocam que essa "violência tem 
a capacidade de atingir seus agredidos de duas formas: pela dor de ser agredido e pelo fato de o agressor ser alguém com quem mantém uma relação de proximidade." (p. 132)

Nota-se então que essa violência atravessa a vivência e dinâmica familiar se colocando enquanto algo que a configura e que se faz presente com a intencionalidade de fazer o sujeito retornar ao ideal que Ihe foi colocado pelas expectativas alheias. Expectativas estas que se estruturam pelo modelo binário e heteronormativo de se estar no mundo e as quais determinam como se estabelece a convivência nas relações familiares.

Romper com tais expectativas cultivadas em toda a estrutura familiar e admitir a existência de um membro que destoe do modelo esperado para as práticas sexuais e afetivas, implica em romper também com laços simbólicos que mantém o contexto familiar organizado, visto que seu funcionando se dá pela manutenção da correspondência de seus membros com o referencial predominante de sexualidade. Esse rompimento e possibilidade de perda de modelo referencial, traz então, também, uma perda do sentimento do que é ser uma família (Teixeira \& Toledo, 2013). Nesse sentido, a partir de seus estudos, os autores afirmam que as famílias não admitem a ideia de pessoas dissidentes sexuais enquanto pertencentes a esse contexto familiar, buscando negar de toda forma possível um eventual membro - filhos, filhas, conjugues ou qualquer parente - de se expressar fora dos enquadres da heteronormatividade, considerando-o um transgressor.

Nos contextos familiares que envolvem a relação de pais e mães heterossexuais e filhos homossexuais, essa quebra de expectativa se relaciona também com uma ruptura dos planos e projetos previamente nutridos pelos país sobre a vida dos seus filhos, como os sonhos de terem netos e uma continuação da família - que não necessariamente ficam impossibilitados, mas, pelo pensamento enraizado da constituição e perpetuação de família somente com base em casais heterossexuais, aparentam, para esses pais, estarem ameaçados (Soliva \& Silvia, 2014; Teixeira E Toledo, 2013).
Com relação aos homens homossexuais, a pesquisa de Silva et al. (2015) traz que essa expectativa envolve também o campo do exercício profissional, estando presente o desejo dos pais de que esse filho se mantenha discreto sobre sua identidade sexual, não se expondo com determinados comportamentos para que alcance posições satisfatórias em sua carreira.

Os autores Soliva e Silva (2014) pontuam em sua pesquisa o sentimento de medo que se instaura nos pais em decorrência dessa ruptura dos projetos como um dos fenômenos geradores das práticas de repressão, as quais visam utilizar de violência de natureza física e/ou psicológica como modo de recuperar esses projetos supostamente perdidos. Como consequência, são causados nos sujeitos homossexuais sofrimento psíquico decorrente de "danos emocionais que se arrastarão por toda uma vida, marcando profundamente sua subjetividade" (p. 138), assim como seus modos de interagir e se inserir socialmente.

Para além do sentimento de medo, a pesquisa de Soliva e Silva (2014) traz como algo persistente nas falas dos seus entrevistados o sentimento de culpa que os pais sentem pela revelação da homossexualidade de seus filhos, tomando para si uma responsabilidade sobre a vivência sexual dos filhos concomitante a ideia de que caberia a eles ter, de algum modo, evitado que seus filhos fugissem à regra heterossexual.

Teixeira e Toledo (2013) corroboram com tal perspectiva ao trazerem em seu estudo o sofrimento e sentimento de decepção que muitas vezes acompanha o saber dos pais sobre a dissidência sexual de seus filhos, vista a perda da expectativa colocada sobre esses sujeitos e suas orientações sexuais. Em alguns casos, os pais sentem-se responsáveis por falhar no processo de "educação" de seus filhos, usando isso como um modo de justificar algo que não conseguem lidar plenamente e Ihe causa sofrimento; sendo necessário a eles um processo de elaboração de luto pelas expectativas perdidas e projeto que precisam ser reelaborados (Teixeira \& Toledo, 2013). 
Outro fator de influência nos contextos de homofobia intrafamiliar, diz respeito à questão financeira enquanto um dos determinantes para a manutenção dessa violência e ferramenta utilizada para a subordinação dos filhos homossexuais. Em muitos casos, há dependência financeira dos filhos para com os pais, em decorrência dos processos longos de escolaridade e/ou dificuldade para exercer uma profissão e se estabelecer no mercado de trabalho, o que se coloca como um obstáculo no processo de ganho de autonomia e liberdade por parte desses indivíduos para vivenciar de maneira plena a sua sexualidade. (Teixeira \& Toledo, 2013; Soliva e Silva, 2014).

Sendo assim, essa incapacidade do filho se sustentar, garantir sua autonomia financeira e afirmar a sua independência é utilizada pelos pais como um mecanismo de controle, pelo qual os mesmos ameaçam a retirada desse suporte material indispensável - tanto para a manutenção dos estudos, quanto para despesas básicas de sobrevivência - de modo a reafirmar a necessidade econômica que os filhos tem deles, obrigando-os, em decorrência disso, a estarem submetidos à vontade que é colocada.

Nessa perspectiva, os autores Teixeira e Toledo (2013) trazem um outro determinante que age nesse processo: o gênero. Segundo os autores, essa dependência de ordem financeira, a qual gera o controle e a obrigação dos filhos de se submeterem aos desejos dos pais, reflete de forma mais grave entre as mulheres devido às concepções machistas que imperam na sociedade e tem como consequência uma dificuldade ainda maior das mulheres de terem acesso ao mercado profissional e alcançarem sua liberdade tanto econômica quanto de expressão de identidade sexual.

Outros modos de violência aos quais essas pessoas são subjugadas diz respeito a desqualificação a qual tanto a sua identidade quanto a sua capacidade de falar por si sobre seus desejos homoeróticos. Há, como reação dos familiares sobre a descoberta da homossexualidade, falas depreciativas sobre homossexualidade que a põe numa posição de loucura, indecência ou "falta do que fazer" (Braga et al., 2018). Nesse sentido, os próprios sujeitos têm a autonomia sobre suas identidades retiradas e são infantilizados e tidos como incapazes de afirmar sua sexualidade de modo consciente e seguro. Desse modo, não somente há uma exclusão dessas pessoas dos momentos de sociabilidade em diferentes ambientes inclusive o familiar -, mas também são excluídas do direito de comunicar abertamente sobre si mesmas, suas identidades, ou defender-se das violações vividas (Teixeira \& Toledo, 2013).

Por outro lado, o não falar sobre essa homossexualidade de um membro familiar trata-se também de uma prática homofóbica importante de ser identificada. Tal como o silenciamento imposto aos sujeitas homossexuais se caracteriza como uma violência que desqualifica tanto o indivíduo quanto o seu desejo homoerótico, atitudes dos pais "fingindo não ver" a homossexualidade do (a) filho (a) também evidencia uma negação dessa identidade e uma tentativa de, ao evitar o tema, fazer com que as práticas homossexuais sejam invisibilizadas, contidas e reprimidas (Perucchi, Brandão \& Vieira, 2014; Braga, et al., 2018).

Todos essas diferentes modalidades de violação de direitos - o silenciamento, invisibilização, ameaças, desqualificação, controle, vigilância, chantagens, proibições, agressões físicas e etc. - são características inerentes dos conflitos que marcam os processos negativos de revelação ou descoberta de filhos que divergem da norma heterossexual, como modo de reproduzir um caráter normatizador por meio de humilhações e constrangimentos (Soliva \& Silva, 2014) e com consequências, a curto ou longo prazo, diretas na saúde mental dos sujeito.

Um estudo mencionado por Braga et al. (2018) esclarece os impactos desse sofrimento psíquico advindo da rejeição familiar ao citar alguns fenômenos percebidos nos sujeitos que vivenciam a homofobia intrafamiliar, sendo eles: ideação e tentativa de suicídio, isolamento social, baixa no desempenho acadêmico, diminuição da autoestima e depressão. Além disso, outra pesquisa, comparando as vivências de sujeitos que, ao revelar a sua homossexualidade, tiveram reações positivas e jovens os quais a família reagiu de modo punitivo, demonstrou que essa rejeição gerou 
"oito vezes mais probabilidades de tentativa de suicídio, seis vezes mais probabilidade de terem depressão, três vezes mais propensão a usarem drogas ilegais e três vezes mais probabilidade de terem uma relação sexual desprotegida" (p. 1296).

Ainda sobre os possíveis modos de manifestação desse sofrimento psíquico desses jovens vítimas de violência, Zanatta et al. (2018) pontua em sua pesquisa, para além dos fenômenos anteriormente citados, as práticas de automutilação e alterações negativas na autoimagem e autoconceito, o que torna evidente a necessidade de acolhimento, cuidados e acompanhamento psicológico para que essas pessoas possam tentar superar os traumas vivenciados e ressignificar os modos de se perceber, se expressar e de estar no mundo.

\section{Considerações Finais}

O processo de revelação da homossexualidade por jovens em seus contextos intrafamiliares é, usualmente, marcado pela homofobia que motiva conflitos turbulentos, tendo em vista a influência direta que os discursos pautados no modelos hegemônicos exercem na organização e funcionamento da dinâmica familiar, a qual deve ser orientada pelo binarismo e a heteronormatividade compulsoriamente reafirmados como os únicos modos de existir.

Nesse sentido, a família deixa de se apresentar como promotora de bem-estar e cuidado, atuando como instrumento de reforço e imposição dessa regra social, negando as identidades que destoem da norma. Para isso, utilizando de mecanismos de violência que se manifestam em graus variados, indo desde o ignorar a existência da homoafetividade e o silenciamento sobre as mesmas, até a segregação do membro da família e práticas de violação de direitos que impeçam a expressão da liberdade e da autonomia dos sujeitos sobre seus desejos sexuais.
Nota-se nos artigos selecionados a atenção à questão sobre os modos que essas violências se apresentam. Os autores, além de relatar a presença de ameaças, vigilância, ofensas, controle e agressões, evidenciam o fato dessas condutas reguladoras serem muitas vezes naturalizadas e expressas cotidianamente na vida dos jovens dissidentes sexuais, tendo efeitos na sua saúde mental e nos modos de se relacionarem nos diferentes meios sociais.

A presente pesquisa conseguiu responder a sua questão central sobre quais os processos psicossociais decorrentes da homofobia no contexto intrafamiliar, entendendo esses processos como gerador de sofrimento psíquico, haja vista a vivência contínua e cotidiana em um ambiente de violências verbais, psicológicas, simbólicas e físicas. Percebese, a partir dos estudos realizados, que os sujeitos que vivenciam tais conflitos, tendem a apresentar comportamentos de autoagressão ou de alto risco, assim como pensamentos e visões de mundo e de si mesmo que podem estar distorcidos em decorrência da exclusão, das humilhações e constrangimentos os quais são submetidos.

Destaca-se enquanto limitações desse estudo a delimitação do idioma para português, condição que restringiu a possibilidade de entrada de artigos internacionais que pudessem tornar o estudo mais robusto, assim como foi proposto nesse estudo um padrão criterioso de extração de dados, limitando-se aos critérios de elegibilidade adotados, condição que inviabilizou outras combinações de descritores, as quais pudessem ampliar a discussão do objeto de estudo.

Enquanto proposta, coloca-se a importância de se voltar a atenção a esse contexto das relações intrafamiliares, pondo em questão a legitimidade dada à instituição familiar para exercer esse poder opressivo produtor de sofrimento; bem como tratando da importância fundamental de espaços, redes de acolhimento e políticas de atenção à população vítima dessa discriminação, pensando meios de tornar esse processo menos doloroso e mais seguro para esses indivíduos. 


\section{Contribuições das autoras}

Cruz, H. A. B. e Oliveira, L. C. realizaram a pesquisa integrativa, fez extração e discussão de dados, assim como a redação do artigo. Araújo, R. L. M. S. revisou criticamente o artigo e contribuiu com a redação do artigo.

\section{Conflitos de interesses}

Nenhum conflito financeiro, legal ou político envolvendo terceiros (governo, empresas e fundações privadas, etc.) foi declarado para nenhum aspecto do trabalho submetido (incluindo mas não limitando-se a subvenções e financiamentos, participação em conselho consultivo, desenho de estudo, preparação de manuscrito, análise estatística, etc.).

\section{Referências}

Braga, I. F., Oliveira, W. A. D., Silva, J. L., Mello, F. C. M., \& Silva, M. A. I. (2018). Violência familiar contra adolescentes e jovens gays e lésbicas: um estudo qualitativo. Revista Brasileira de Enfermagem-REBEn, 71(suppl 3),1295-303. doi: 10.1590/0034-7167-2017-0307

Ceccarelli, P. R. (2008). A invenção da homossexualidade. BagoasEstudos gays: gêneros e sexualidades, 2(02),71-93.

Silva, M. M. L., Frutuozo, J. F. F., Feijó, M. R., Valerio, N. I., \& Chaves, U. H. (2015). Família e orientação sexual: dificuldades na aceitação da homossexualidade masculina. Temas em Psicologia, 23(3), 677-692. doi: 10.9788/TP2015.3-12

Louro, G. L. (2004). Os estudos feministas, os estudos gays e lésbicos e a teoria queer como políticas de conhecimento. Imagem e diversidade sexual. São Paulo: Nojosa, 23-28.

Mendes, K. D. S., Silveira, R. C. C. P., \& Galvão, C. M. (2008). Revisão integrativa: método de pesquisa para a incorporação de evidências na saúde e na enfermagem. Texto \& contexto enfermagem, 17(4),758-64. doi: $10.1590 /$ S0104-07072008000400018

Nascimento, G. C. M., \& Scorsolini-Comin, F. (2018). A Revelação da homossexualidade na família: revisão integrativa da literatura científica. Temas em Psicologia, 26(3), 1527-1541. doi: 10.9788/tp2018.3-14pt
Oliveira, L. (2019). A "vergonha" como uma "ofensa": homossexualidade feminina, família e micropolíticas da emoção. Horizontes Antropológicos, (54), 141-171. doi: 10.1590/s0104-71832019000200006

Perucchi, J., Brandão, B. C., \& Vieira, H. I. S. (2014). Aspectos psicossociais da homofobia intrafamiliar e saúde de jovens lésbicas e gays. Estudos de Psicologia, 19(1), 67-76. doi: 10.1590/S1413-294X2014000100009

Rodrigues, C., \& BUTLER, J. P. (2005) Problemas de gênero: feminismo e subversão da identidade. Revista Estudos Feministas, 13(1),216. doi: 10.1590/S0104026X2005000100012

Sarti, C. A. (2004). A família como ordem simbólica. Psicologia usp, 15(3), 11-28. doi: 10.1590/S0103-65642004000200002

Soliva, T. B., \& Silva Junior, J. B. (2014). Entre revelar e esconder: pais e filhos em face da descoberta da homossexualidade. Sexualidad, Salud y Sociedad-Revista Latinoamericana, (17), 124-148. doi: 10.1590/1984-6487.sess.2014.17.08.a

Toledo, L. G., \& Teixeira Filho, F. S. (2013). Homofobia familiar: abrindo o armário 'entre quatro paredes'. Arquivos Brasileiros de Psicologia, 65(3), 376-391.

Zanatta, E. A., Ferraz, L., Klein, M. L., Marques, L. C., \& Ferraz, L. (2018). Descobrir, aceitar e assumir a homoafetividade: situações de vulnerabilidade entre jovens/Discovering, accepting and assuming homoaffectivity: situations of vulnerability among young people. Revista de Pesquisa: Cuidado é Fundamental Online, 10(2), 391-398. doi: 10.9789/2175-5361.2018.v10i2.391-398 